archives.gov/sites/default/files/docs/national_action_plan_for_combating antibotic-resistant_bacteria.pdf

3 Assicot M, Gendrel D, Carsin H, Raymond J, Guilbaud J, Bohuon C. High serum procalcitonin concentrations in patients with sepsis and infection. Lancet 1993;341:515-518.

4 Kip MM, Kusters R, IJzerman MJ, Steuten LM. A PCT algorithm for discontinuation of antibiotic therapy is a cost-effective way to reduce antibiotic exposure in adult intensive care patients with sepsis. J Med Econ 2015;18:944-953.

5 Schuetz P, Christ-Crain M, Thomann R, Falconnier C, Wolbers M, Widmer I, Neidert S, Fricker T, Blum C, Schild U, et al.; ProHOSP Study Group. Effect of procalcitonin-based guidelines vs standard guidelines on antibiotic use in lower respiratory tract infections: the ProHOSP randomized controlled trial. JAMA 2009;302:1059-1066.

6 Bouadma L, Luyt CE, Tubach F, Cracco C, Alvarez A, Schwebel C, Schortgen F, Lasocki S, Veber B, Dehoux M, et al.; PRORATA trial group. Use of procalcitonin to reduce patients' exposure to antibiotics in intensive care units (PRORATA trial): a multicentre randomised controlled trial. Lancet 2010;375:463-474.

7 Christ-Crain M, Jaccard-Stolz D, Bingisser R, Gencay MM, Huber PR, Tamm M, Müller B. Effect of procalcitonin-guided treatment on antibiotic use and outcome in lower respiratory tract infections: cluster-randomised, single-blinded intervention trial. Lancet 2004; 363:600-607.

\section{Epithelial Mesenchymal Transition in Chronic Obstructive Pulmonary Disease, a Precursor for Epithelial Cancers: Understanding and Translation to Early Therapy}

\section{To the Editor:}

We read with interest the recent editorial by Nichole T. Tanner and colleagues, published in the AnnalsATS, considering the lethal association between chronic obstructive pulmonary disease (COPD) and lung cancer that highlighted the potential causal role of epithelial mesenchymal transition (EMT) in this link (1). Understanding these mechanisms is much needed for translation to early, and potentially even preventative, therapy. It is encouraging and reassuring that leading clinical respiratory journals are now recognizing this, as it has been difficult to obtain data on such a novel concept published in high-profile journals.

Human epidemiological studies strongly suggest that patients receiving high-dose inhaled corticosteroids have an appreciable (50\%) reduction in the risk for lung cancer (2). We have hypothesized that EMT might be the process through which this effect of inhaled corticosteroids occurs. Thus, in a proof-ofconcept randomized controlled trial, we reported that inhaled fluticasone propionate delivered in high doses over the course of 6 months did suppress airway epithelial activation and EMT-related changes in large airways of patients with COPD (3). This was the first study to report anti-EMT effects of inhaled corticosteroids in COPD. If this hypothesis is indeed correct, it has major implications for treating/preventing both obstructive airway fibrosis and lung cancer, although a more safe drug than steroids in these doses would be ideal for long-term use.

We were the first to report that EMT is an active process in both small and large airways of smokers and patients with COPD and was related to reduced lung function in $\operatorname{COPD}(4,5)$. Several

This work was supported by Clifford Craig Foundation
8 Nobre V, Harbarth S, Graf JD, Rohner P, Pugin J. Use of procalcitonin to shorten antibiotic treatment duration in septic patients: a randomized trial. Am J Respir Crit Care Med 2008;177: 498-505.

9 Hochreiter M, Köhler T, Schweiger AM, Keck FS, Bein B, von Spiegel T, Schroeder S. Procalcitonin to guide duration of antibiotic therapy in intensive care patients: a randomized prospective controlled trial. Crit Care 2009;13:R83.

10 Rhodes A, Evans LE, Alhazzani W, Levy MM, Antonelli M, Ferrer R, Kumar A, Sevransky JE, Sprung CL, Nunnally ME, et al. Surviving Sepsis Campaign: international guidelines for management of sepsis and septic shock: 2016. Crit Care Med 2017;45:486-552.

11 Soni NJ, Samson DJ, Galaydick JL, Vats V, Huang ES, Aronson N, Pitrak DL. Procalcitonin-guided antibiotic therapy: a systematic review and meta-analysis. J Hosp Med 2013;8:530-540.

12 Chu DC, Mehta AB, Walkey AJ. Practice patterns and outcomes associated with procalcitonin use in critically ill patients with sepsis. Clin Infect Dis 2017;64:1509-1515.

13 Balk RA, Kadri SS, Cao Z, Robinson SB, Lipkin C, Bozzette SA. Effect of procalcitonin testing on health-care utilization and costs in critically ill patients in the united states. Chest 2017; 151:23-33.

Copyright () 2017 by the American Thoracic Society

other groups have since confirmed these findings. In the large airways, we found that active EMT is present and is associated with hypervascularity of the reticular basement membrane. This gives the typical appearance of active type $3 \mathrm{EMT}$, which is considered a premalignant condition. It is important to note that it is large airways where most of the squamous cell carcinomas occur, and type 3 EMT could be central to this. The other key pathology associated with COPD is small airway or peribronchiolar fibrosis and obliteration, and this could potentially be related to active type 2 EMT at this site, but fibrosis in general is also associated with malignancy (5).

Very recently, we also reported active EMT in the leading edge of invasive nonsmall cell lung cancer, both squamous and adeno cell types, with the aggressiveness of the tumors being strongly related to the activity of their EMT (6). Further, EMT activity within the tumors closely related to EMT activity in nontumoraffected airway wall epithelium. This work suggests that the level of EMT activity in the airway wall, even in large airways amenable to bronchoscopic biopsy, could potentially be used as a marker for smokers most likely to develop both COPD and lung cancer.

In summary, we appreciate that major journals are beginning to recognize that epithelial activation and basal cell reprogramming with EMT (and epithelially related vessel changes) may represent fundamentally important aspects of COPD pathology, including the severe sequelae of airway fibrosis and cancer development. Indeed, we may now be getting into a position that allows an integrated understanding of this airway disease, with the potential to be translated into a new paradigm for earlier or even preventive therapy, attacking fundamental disease mechanisms rather than symptoms and clinical exacerbations in later-stage patients.

Author disclosures are available with the text of this letter at www.atsjournals.org.

Sukhwinder Singh Sohal, Ph.D.

University of Tasmania

Launceston, Australia 
Philip M. Hansbro, Ph.D.

The University of Newcastle

Newcastle, New South Wales, Australia

Eugene Haydn Walters, M.D., D.M., D.Sc.

University of Tasmania

Launceston, Australia

\section{References}

1 Tanner NT, Pastis NJ. Chronic obstructive pulmonary disease as a lung cancer risk: worth its weight in "GOLD". Ann Am Thorac Soc 2017;14:309-310.

2 Parimon T, Chien JW, Bryson CL, McDonell MB, Udris EM, Au DH. Inhaled corticosteroids and risk of lung cancer among patients with chronic obstructive pulmonary disease. Am J Respir Crit Care Med 2007;175:712-719.

3 Sohal SS, Soltani A, Reid D, Ward C, Wills KE, Muller HK, Walters EH. $A$ randomized controlled trial of inhaled corticosteroids (ICS) on

\section{Unilateral High-Altitude Pulmonary Edema}

\section{To the Editor:}

We read with great interest the paper by Cherian and Estrada-Y-Martin (1) discussing a case of unilateral pulmonary edema at high altitude. We have also reported a case of unilateral high-altitude pulmonary edema (HAPE) in a subject with a previously known right pulmonary artery hypoplasia (2). The discussion of our case confirms the theory of overperfusion cited in the Cherian article; in fact, pulmonary edema was limited to the lung without pulmonary artery hypoplasia. Both cases underline the importance of hemodynamic factors in the development of HAPE. There is a strong individual predisposition to HAPE, with a marked pulmonary vascular response to hypoxia and exercise (3). Susceptibility to HAPE is also reported in people with congenital or acquired limitation of the pulmonary vascular bed and/or pulmonary hypertension $(3,4)$. In these conditions, development of HAPE is possible at an altitude lower than the one related in classical cases $(3,4)$. Another condition reported as a possible risk factor for HAPE is the presence of a patent foramen ovale (5). Patent foramen ovale is not uncommon, as it is present in approximately $25 \%$ of the general population. Some papers suggest that in the presence of patent foramen ovale, sudden ascent to high altitude may create a vicious circle, with the pulmonary hypertension, induced by the hypobaric alveolar hypoxia, leading to a right-to-left shunt that worsens the hypoxemia. In fact, the major determinant of hypoxic vasoconstriction is alveolar hypoxia (6), but systemic and bronchial arterial $\mathrm{PO}_{2}$ and mixed venous $\mathrm{PO}_{2}$ (reduced by exercise in a hypobaric environment) also contribute to a lesser degree and in an additive fashion (6).

\section{Reply: Unilateral Pulmonary Edema after Visiting High Altitude}

\section{From the Authors:}

We thank Drs. Fiorenzano and Dottorini for their interest and comments about our article, "Unilateral Pulmonary Edema after Visiting High Altitude" (1) in the Clinical Physiologist section. markers of epithelial-mesenchymal transition (EMT) in large airway samples in COPD: an exploratory proof of concept study. Int J Chron Obstruct Pulmon Dis 2014;9:533-542.

4 Sohal SS, Reid D, Soltani A, Ward C, Weston S, Muller HK, Wood-Baker R, Walters EH. Reticular basement membrane fragmentation and potential epithelial mesenchymal transition is exaggerated in the airways of smokers with chronic obstructive pulmonary disease. Respirology 2010; 15:930-938.

5 Mahmood MQ, Sohal SS, Shukla SD, Ward C, Hardikar A, Noor WD, Muller HK, Knight DA, Walters EH. Epithelial mesenchymal transition in smokers: large versus small airways and relation to airflow obstruction. Int J Chron Obstruct Pulmon Dis 2015;10:1515-1524.

6 Mahmood MQ, Ward C, Muller HK, Sohal SS, Walters EH. Epithelial mesenchymal transition (EMT) and non-small cell lung cancer (NSCLC): a mutual association with airway disease. Med Oncol 2017;34:45.

\section{Copyright @ 2017 by the American Thoracic Society}

Even in the absence of studies specifically assessing the risk, patients with known congenital or acquired conditions that may cause overperfusion and/or hypertension of the pulmonary vascular bed should be advised to take preventive measures before high-altitude travels $(3,4)$.

Author disclosures are available with the text of this letter at www.atsjournals.org.

Giuseppe Fiorenzano, M.D.

Azienda Ospedaliera Universitaria "S. Maria"

Terni, Italy

Maurizio Dottorini, M.D.

Azienda Ospedaliera Universitaria Perugia

Perugia, Italy

\section{References}

1 Cherian SV, Estrada-Y-Martin RM. Unilateral pulmonary edema after visiting high altitude. Ann Am Thorac Soc 2017;14:589-593.

2 Fiorenzano G, Rastelli V, Greco V, Di Stefano A, Dottorini M. Unilateral high-altitude pulmonary edema in a subject with right pulmonary artery hypoplasia. Respiration 1994;61: 51-54.

3 Maggiorini M. High altitude-induced pulmonary oedema. Cardiovasc Res 2006;72:41-50.

4 Luks AM, Swenson ER. Travel to high altitude with pre-existing lung disease. Eur Respir J 2007;29:770-792.

5 Levine BD, Grayburn PA, Voyles WF, Greene ER, Roach RC, Hackett PH. Intracardiac shunting across a patent foramen ovale may exacerbate hypoxemia in high-altitude pulmonary edema. Ann Intern Med 1991; 114:569-570.

6 Swenson ER. Hypoxic pulmonary vasoconstriction. High Alt Med Biol 2013;14:101-110.

Copyright @ 2017 by the American Thoracic Society

We agree that their published report (2), which described the development of unilateral high-altitude pulmonary edema (HAPE) in the setting of right pulmonary artery hypoplasia, is very similar to our case. Their case also reports the development of pulmonary edema in the lung with the normal pulmonary circulation. We agree with them that hypoxia-associated pulmonary vasoconstriction is key to the development of HAPE in susceptible individuals. This is heightened in congenital conditions associated with increased pulmonary blood flow, as 
Reproduced with permission of copyright owner. Further reproduction prohibited without permission. 